\title{
SPECTROPHOTO-ELECTRICAL SENSITIVITY OF SOME HALIDE SALTS OF THALLIUM, LEAD, AND SILVER.
}

\author{
By W. W. Coblentz and J. F. Eckford.
}

ABSTRACT.

The present paper, considered in connection with a previous publication (B. S. Sci. Papers No. 446 and one in press), gives the results of a study of the effect of crystal structure, chemical constitution, and atomic weight upon spectrophoto-electrical sensitivity. It is shown that these three factors have a definite effect upon the photo-electrical reaction, just as previously they were found to have a specific effect upon absorption and reflection spectra.

Spectrophoto-electrical sensitivity data are given on ( $x$ ) the chloride, bromide, and iodide of thallium; (2) the iodide of lead; and (3) the chloride, bromide, and iodide of silver. It is shown that the photo-electrical reaction of these salts is confined to a very narrow region of the spectrum, being even more sharply defined than that of photo-electrical gas-ionic conduction spectra of the alkali metals.

The effect of increasing the atomic weight is to shift the maximum of the photoelectrical reaction toward the long wave lengths.

\section{CONTENTS.}

I. Introduction

Page.

II. Experimental procedure . . . . . . . . . . . . . .

III. Photo-electrical data on some thallium salts................ 49 I

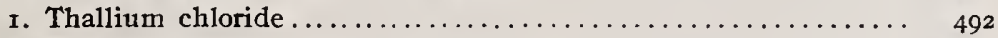

2. Thallium bromide $\ldots \ldots \ldots \ldots \ldots \ldots \ldots \ldots \ldots \ldots \ldots \ldots \ldots \ldots \ldots, 493$

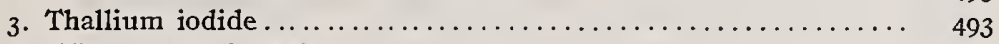

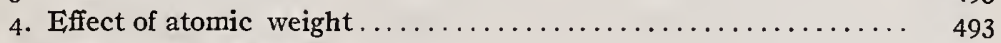

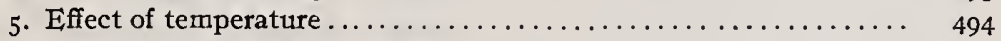

IV. Photo-electrical data on some lead salts................... 494

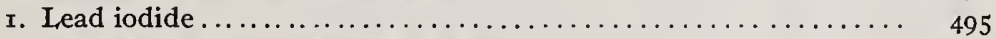

V. Photo-electrical data on some silver salts................... 495

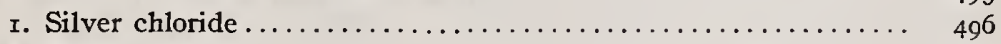

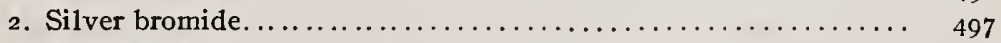

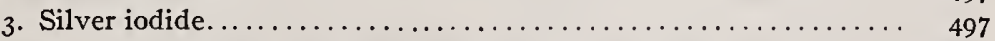

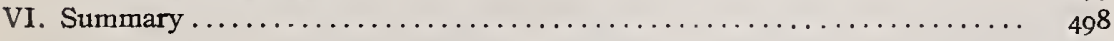

\section{INTRODUCTION.}

With the accumulation of data on the spectrophoto-electrical conduction in various substances as affected by crystal structure, chemical constitution, etc., apparent analogies are being found $12793^{\circ}-22$ 
between photo-electrical reaction spectra and absorption spectra. For example, in a previous investigation of the spectrophotoelectrical reaction of silver sulphide ${ }^{1}$ in the isometric form argentite and in the orthorhombic form acanthite, it was found that while crystal structure is not the underlying cause of photoelectrical sensitivity it has a marked effect upon the reaction to radiation of different wave lengths of the spectrum. The absorption of thermal radiation in passing through a crystalline substance exhibits analogous effects.

Again, as previously observed in investigations of transmission spectra, in which it was shown that the absorption spectrum of a compound is not the composite of the absorption bands of the constituents, so in spectrophoto-electrical reaction spectra it appears that the reaction of the compound is not the sum of the spectral reactions of the constituents. For example, it was found that the photo-electrical reaction spectrum of the double sulphide of silver and of antimony, pyrargyrite ${ }^{2}\left(\mathrm{Ag}_{3} \mathrm{SbS}_{3}\right)$, is not the composite of the reactions of the constituents, silver sulphide ${ }^{3}\left(\mathrm{Ag}_{2} \mathrm{~S}\right)$, and stibnite $\left(\mathrm{Sb}_{2} \mathrm{~S}_{3}\right)$, both of which minerals have characteristic photo-electrical reaction spectra.

On the other hand, as observed in absorption spectra, there is a similarity in the spectrophoto-electrical reaction spectra of pyrargyrite $\left(\mathrm{Ag}_{3} \mathrm{SbS}_{3}\right)$ and proustite ${ }^{4}$ which are similar in chemical structure.

The object of the present contribution to the subject of photoelectrical conduction is to present data on the effect of atomic weight upon the position of characteristic spectrophoto-electrical reaction bands, the maxima of which shift toward the long wave lengths with increase in atomic weight of the variable constituent (whether acid or base). This is similar to the shift of the characteristic bands of selective reflection with increase in the atomic weight of the basic element observed ${ }^{5}$ in carbonates, sulphates, etc. From these data it appears that atomic weight, crystal structure, and chemical constitution have a marked effect upon photo-electrical reaction spectra, as previously observed in absorption and reflection spectra. From this it would appear that the source of the photo-electrical reaction is to be sought for within the molecule.

\footnotetext{
1 B. S. Sci. Papers, No. 344 (acanthite) and No. 446 (argentite).

3 B. S. Sci. Papers now in press (pyrargyrite).

${ }^{3}$ B. S. Sci. Papers, Nos. 344 and 446 (silver sulphide); B. S. Sci. Papers, No. 398 (stibnite).

B. S. Sci. Papers, No. $4^{12}$ (proustite)

${ }_{5}^{5}$ Coblentz, Investigations of infra-red spectra, Pub. Nos. 65 and 97 , Carnegie Institute of Washington.
} 
The photo-electrical reaction curves, especially those of the halide salts of thallium, given in this paper, have the outline of what appears to be the typical spectrophoto-electrical reaction curve, namely, a high photo-electrical reaction, extending over a wide spectral region, on the short wave length side of the maximum and a very abrupt termination of the reaction on the long wave length side of the maximum.

These substances have a high absorption with a probable anomalous dispersion in the ultra-violet. As pointed out in previous papers, the typical spectrophoto-electrical reaction curve appears to be the reverse of the typical anomalous dispersion curve. Hence, in searching for an explanation, perhaps it may be possible to attribute these two phenomena to a common cause.

\section{EXPERIMENTAL PROCEDURE.}

The apparatus and procedure was essentially the same as used in previous investigations on this subject. For measurements in the visible spectrum the source of spectral radiation was a 60o-watt tungsten lamp (calibrated for equal energy) and a lens spectrometer of high-light-gathering power. For measurements in the ultraviolet a quartz spectropyrheliometer ${ }^{6}$ was used, the source of radiation being a quartz mercury arc lamp, emitting strong lines at $0.305,0.313,0.334,0.365,0.405$, and $0.436 \mu$, reduced to equal intensity, as previously described. In Figure I the dotted parts of the curves for $\mathrm{Tl} \mathrm{Br}$ and $\mathrm{Tl} \mathrm{I}$ represent the observations in the ultra-violet, using the emission lines of quartz for the radiation stimulus.

All the photosensitive substances described in this paper responded very quickly to radiation stimuli, the photo-electrical reaction attaining a maximum in two to three seconds, which was the time of swing of the galvanometer needle. The measurements were made at room temperature $\left(22^{\circ} \mathrm{C}\right.$.) unless otherwise noted in the text. None of these substances were found to be sensitive to intra-red rays.

\section{PHOTO-ELECTRICAL DATA ON SOME THALLIUM} SALTS.

Through the courtesy of the Case Research Laboratory an opportunity was presented to examine the halogen salts of thallium ( $\mathrm{Tl} \mathrm{Cl}$, Tl $\mathrm{Br}$, and $\mathrm{Tl} \mathrm{I}$ ). The material was in the form of thin

${ }_{6}^{6}$ B. S. Sci. Papers, 16, D. 233; r920.

$12793^{\circ}-22-2$ 
films melted on a disk of quartz about $25 \mathrm{~mm}$ in diameter. The electrodes were in the form of a comblike grid of gold painted on the surface. This material had a high resistance. Additional samples were, therefore, prepared by melting a thick ( 0.3 to 0.5 $\mathrm{mm}$ ) layer of the salt upon a glass plate. The electrodes were of Wood's alloy, melted upon the surface of the salt, applied in such a manner that there was a clear surface of the salt about I mm wide and ro to $2 \mathrm{~mm}$ long for exposure to the spectral radiation stimulus.

\section{THALLIUM CHLORIDE.}

Owing to the high resistance and leakage from mositure it was difficult to obtain sufficient sensitivity and steadiness for observa-

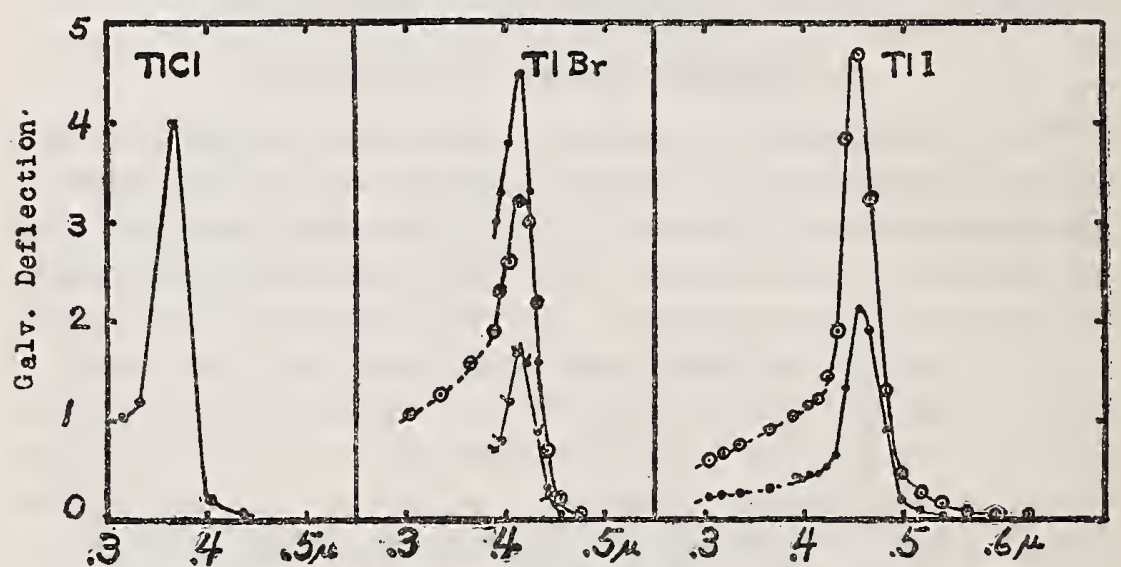

Fig. I.-Spectrophoto-electrical reaction curves of the chloride, bromide, and iodide of thallium.

tions. The position of the maximum of spectrophoto-electrical sensitivity was therefore first predicted, from a plot of atomic weights of $\mathrm{Br}$ and I against the maxima of spectrophoto-electrical sensitivity of $\mathrm{Tl} \mathrm{Br}$ and $\mathrm{Tl} \mathrm{I}$, to be at $0.37 \mu$. This prediction was verified by focusing by means of a quartz lens the total radiation from the quartz mercury vapor lamp upon the samples in front of which was interposed a plate of Corning glass ${ }^{7}(586 \mathrm{~J})$ which had a transmission band between 0.32 and $0.40 \mu$ with a maximum transmission of 37 per cent at $0.365 \mu$. Correcting the observed galvanometer deflection $(3.0 \mathrm{~mm})$ for the absorption of the glass, the deflection would have been $8.1 \mathrm{~mm}$, which is within $\mathrm{I}$ per cent of the observed $(8.0 \mathrm{~mm})$ deflection. From this it appeared

Gibson, Tyndall, and McNicholas, B. S. Tech. Papers, No. I48, Fig. 2 I, curve No. 85. 
that the photo-electrical reaction of the $\mathrm{Tl} \mathrm{Cl}$ is confined practically to a narrow spectral line at about $0.365 \mu$.

Subsequently, by heating and drying the material just before starting the observations the spectrophoto-electrical reaction curve $\mathrm{Tl} \mathrm{Cl}$ (Fig. I, galvanometer deflections in millimeters) was obtained, showing that the maximum of the reaction is confined practically to the line at $0.365 \mu$.

\section{THALLIUM BROMIDE.}

The spectrophoto-electrical reaction of several samples of $\mathrm{T}$ $\mathrm{Br}$ was determined, one of which was especially prepared by this bureau's chemistry division. The various samples give consistent results showing a narrow maximum in the region of $0.413 \mu$. (See Fig. I, galvanometer deflections in millimeters.)

\section{THALLIUM IODIDE.}

The spectrophoto-electrical sensitivity curves (Fig. I, galvanometer deflections in centimeters) of two samples of T1 I are

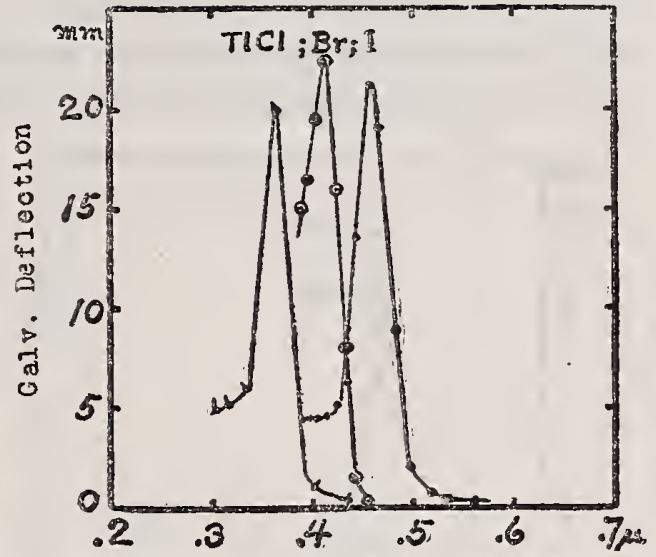

FIG. 2.-Effect of atomic weight upon the maximum of spectrophoto-electrical sensitivity. similar, showing a maximum in the region of $0.455 \mu$. The iodide of thallium was found to be intrinsically more sensitive than either the bromide or the chloride.

\section{EFFECT OF ATOMIC WEIGET.}

The photo-electrical reaction curves of the halide salts of thallium are conspicuous for the narrowness of the spectral region to which the reaction is confined. In common with all substances thus far examined, including the gas-ionic photo-electric cells of the allzali metals ( $\mathrm{Ca}, \mathrm{Na}, \mathrm{K}$ ), the photo-electrical reaction is high on the short wave length side and low on the long wave length side of the maximum. The result is a somewhat unsymmetrical termination of the spectrophoto-electrical reaction curve, which, however, is quite narrow for the thallium salts. (See Fig. 2.)

The graph of the maxima for $\mathrm{Tl} \mathrm{Cl}, \mathrm{T} 1 \mathrm{Br}$, and $\mathrm{Tl}$ I at $0.365 \mu$ $0.4 \mathrm{I} 3 \mu$, and $0.455 \mu$, respectively, plotted against the atomic weight 
of the acid element appears to be a straight line. A somewhat similar shift of the maximum occurs in the gas-ionic photoelectric cells ${ }^{8}$ of $\mathrm{Ca}, \mathrm{Na}, \mathrm{K}, \mathrm{Ca}, \mathrm{Cs}, \mathrm{Rb}$.

\section{EFFECT OF TEMPERATURE.}

The only one of these salts that could be conveniently examined for photosensitivity at low temperatures was $T 1$ I. For this purpose the mirror spectrometer and low temperature equipment previously described ${ }^{9}$ was employed. This permitted making observations to $3 \mu$ in the infra-red, throughout which region this material appears to be insensitive.

The photoelectrical reaction curves at 23 and $-60^{\circ} \mathrm{C}$. (See Fig. 3) are practically identical in position, showing that if there is a shift of the maximum toward the shorter wave lengths as usually

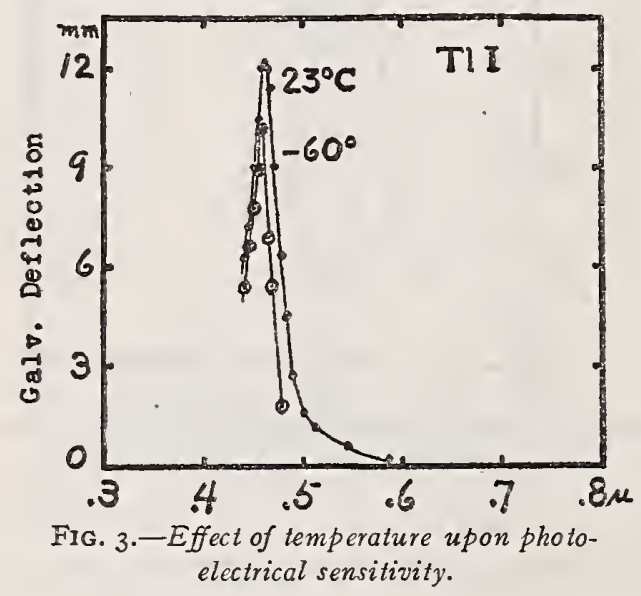
observed in other substances it is not very marked. This is probably to be expected in view of the narrow, symmetrical shape of the spectrophotoelectrical reaction curve.

IV. PHOTO-ELECTRICAL DATA ON SOME LEAD SALTS.

Tests were made for photo-electrical sensitivity of the chloride, bromide, and iodide of lead. The material examined was the high-grade material obtained in commerce without additional purification. The samples were melted upon glass plates and electrodes of Wood's alloy applied, leaving an exposed area from I to $2 \mathrm{~mm}$ wide and about to $\mathrm{mm}$ long.

The samples of the chloride and bromide of lead showed sufficient conductivity in the dark, so that if they had been photoelectrically sensitive it could have been detected. But no change in conductivity was observed when they were exposed to the total radiation from a gas-filled tungsten lamp or that of a quartz mercury arc lamp. For the latter test the radiations from the

${ }^{8}$ Braun, Inaug. Dissertation, Bonn; 1906. B. S. Sci. Papers, 14, p. 517 ; 1918.

'B. S. Sci. Papers, 15, p. 121; Igrg. 
quartz burner were focused upon the sample by means of a cylindrical quartz lens having a focal length of $18 \mathrm{~cm}$ and a diameter of $6 \mathrm{~cm}$.

\section{LEAD IODIDE.}

The iodide of lead was found sensitive photo-electrically and a number of samples were examined, one of these being a sample from the Case Research Laboratory. The latter was mounted upon a quartz disk, with grid electrodes of gold.

In Figure 4 is shown the spectrophoto-electrical reaction of lead iodide $\left(\mathrm{Pb} \mathrm{I}_{2}\right)$. The curve plotted as dots (. . .) represents the observations on a sample obtained from this bureau's chemical laboratory, the distance between the electrodes being $2 \mathrm{~mm}$. The circles $(\odot \odot \odot)$ represent observations on this same sample when

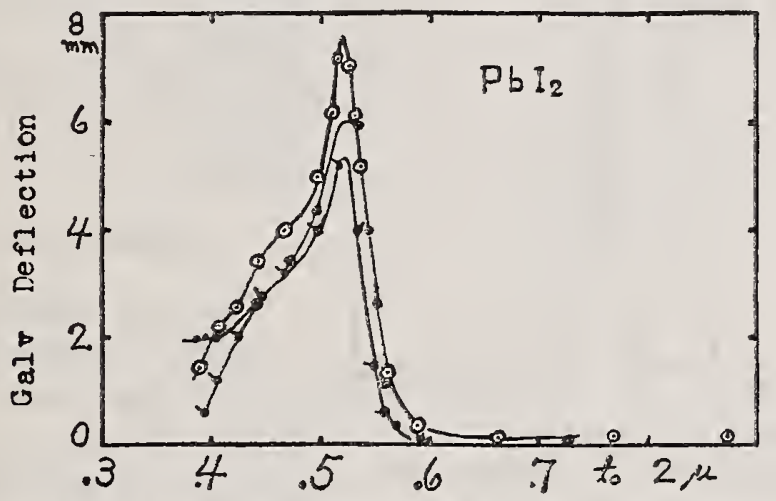

FIG. 4.-Spectrophoto-electrical sensitivity curves of lead iodide.

the electrodes were I $\mathrm{mm}$ apart. In this case the galvanometer deflections were four times that of the preceding example. The observations plotted as commas $(b<)$ were obtained upon the sample from the Case Research Laboratory.

The spectrophoto-electrical sensitivity curves of these samples of lead iodide indicate that the reaction is complex, with an illdefined maximum in the region of $0.45 \mu$ and a narrow, sharply defined maximum at $0.52 \mu$. The iodide of lead does not appear to be at all sensitive photo-electrically to the infra-red and only slightly sensitive to the extreme ultra-violet rays.

V. PHOTO-ELECTRICAL DATA ON SOME SILVER SALTS.

Previous researches of Becquerel, ${ }^{10}$ Scholl, ${ }^{11}$ and others show that the halide salts of silver exhibit a maximum photo-electrical

10 Becquerel, La Lumiere, 2, p. I2 I; 1868.

11 Scholl Ann. der Phys. (4) 16, pp. I93 and 4I7; 1905. 
reaction for radiations in the violet end of the spectrum. For silver iodide (moist membranes) Scholl found that the maximum photo-electrical reaction lies in the region of 0.37 to $0.43 \mu$, which coincides with the region of maximum absorption. In marked contrast with the halide salts of silver, the sulphide of silver ${ }^{12}$ has a small maximum at about $0.42 \mu$ in the violet and a more pronounced maximum in the region of $1.35 \mu$ in the infra-red.

The chloride, bromide, and iodide of silver examined were prepared by $\mathrm{H}$. B. Knowles, of the chemical division. In view of the fact that some of the preparations might contain $\mathrm{K} \mathrm{NO}_{3}$, samples of commercial potassium nitrate, of silver nitrate, and of silver oxide were also tested for photosensitivity, but no photo-electrical

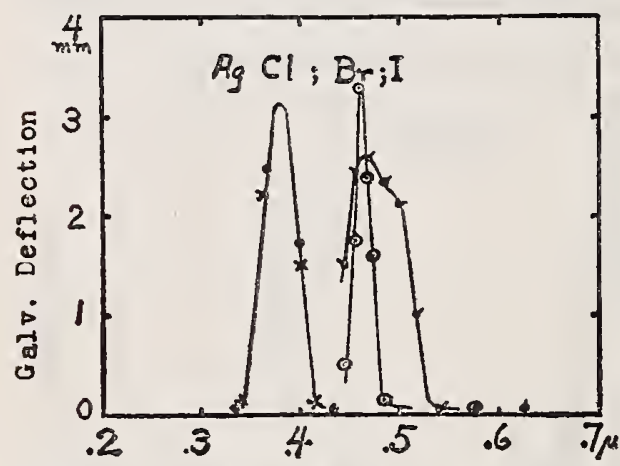

FIG. 5.-Spectrophoto-elcctrical reaction curves of the chloride, bromide, and iodide of silver. reaction was obtained for either of these three substances. Case ${ }^{13}$ mentions that freshly prepared pastiles of silver oxide are sensitive.

\section{SILVER CHLORIDE.}

The first tests of photoelectrical sensitivity. were made upon some vitreous silver chloride which had been melted into thin plates about 15 years ago. The material was in the form of rods 15 by 3 by $\mathrm{I} \mathrm{mm}$. The electrodes were fine wire wound in grooves cut near the ends of the samples. Considerable difficulty was experienced in making observations owing to unsteadiness of the galvanometer. Furthermore, the ultra-violet rays decomposed the material, increasing the dark conductivity. The silver salts, therefore, proved disappointing for demonstrating the effect of atomic weight upon the position of the maximum of spectrophotoelectrical sensitivity.

Several sets of observations are given in Figure 5. The results obtained indicated a sharp band of photo-electrical sensitivity in the region of $0.38 \mu$. The material does not appear to be sensitive to infra-red rays. The freshly prepared crystalline material, also the old material which had recrystallized on cooling, did not exhibit photosensitivity. This is in agreement with the results of other observers. 
Tests were made of samples of vitreous silver chloride to which had been added small amounts of silver oxide. It was found that when the silver oxide was present in small amounts, imparting a bluish-gray color, the sample remained photosensitive. However, on adding considerable silver oxide, so as to impart a dark color, the mixture was photo-electrically insensitive.

\section{SIIVER BROMIDE.}

This material is somewhat hydroscopic. The test samples were, therefore, prepared by melting the salt upon a glass plate and laying across the top of the molten material a smaller plate of glass or quartz, leaving some of the molten salt protruding along the edges. The electrodes were copper or silver wires placed in the protruding salt when in the molten state. When cold, the edges were covered with sealing wax to exclude moisture.

Samples of silver bromide mixed into a paste and dried on glass showed no photo-electrical sensitivity. Samples of silver bromide which were melted into a vitreous mass exhibited photoelectrical sensitivity. A typical curve showing the spectrophotoelectrical reaction of vitreous silver bromide is shown in Figure 5 . The maximum, at $0.46 \mu$, is sharp and confined to a very narrow region of the spectrum.

The first sample examined was covered with a thin plate of quartz, but no photo-electrical sensitivity was observed in the extreme ultra-violet. This substance appears to be photo-electrically insensitive to infra-red rays.

\section{SILVER IODIDE.}

The samples examined were melted between glass plates, with electrodes attached, as with silver bromide. The material recrystallized on cooling. A typical curve showing the spectrophotoelectrical reaction of silver iodide is shown in Figure 5. The curve is wide and complex, with apparently two maxima at about 0.47 and $0.50 \mu$, respectively. In this respect it is like the curve of lead iodide.

Considered as a whole, the halide salts of silver do not exhibit so marked or uniform a shift of the maximum of spectrophotoelectrical reaction, with change in atomic weight of the acid element, as observed in the thallium salts. If we consider the halide element as the active agent, then we find that the iodide is conspicuous for a maximum at 0.46 to $0.48 \mu$ in all three compounds. However, there is nothing to indicate that the photo-electrical reaction can be assigned to the ionization of a particular element. 


\section{SUMMARY.}

This paper, considered in connection with previous publications (Sci. Papers No. 446 and one now in press), completes a study of the effect of crystal structure, chemical constitution, and atomic weight upon spectrophoto-electrical sensitivity. It is shown that these three factors have a definite effect upon the photo-electrical reaction, just as previously they were found to have a specific effect upon absorption and reflection spectra.

It was found that the spectrophoto-electrical reaction of the halide salts of thallium, lead, and silver is confined to a very narrow region of the violet end of the spectrum, being the narrowest and most sharply defined reaction spectra of all substances yet published, including the photo-electric gas-ionic reaction spectra of the alkali metals.

Data are given showing that increasing the atomic weight of the acid element in the salts of thallium shifts the maximum of the spectrophoto-electrical reaction toward the long wave lengths. The maximum of the spectrophoto-electrical sensitivity of $\mathrm{T} 1 \mathrm{Cl}$ is at $0.365 \mu$, of $\mathrm{T} 1 \mathrm{Br}$ at $0.4 \mathrm{I} 3 \mu$, and of $\mathrm{T} 1 \mathrm{I}$ at $0.455 \mu$.

The photo-electrical sensitivity curves of the halide salts of thallium have the outline of what appears to be the typical spectrophoto-electrical reaction curve, namely, a high photoelectrical reaction on the short wave-length side of the maximum and a very abrupt termination of the reaction on the long wavelength side of the maximum. Lowering the temperature of $\mathrm{T} 1 \mathrm{I}$ to $-60^{\circ} \mathrm{C}$. had no appreciable effect upon the position of the maximum of the spectrophoto-electrical reaction.

Of the halide salts of lead $\left(\mathrm{Pb} \mathrm{Cl}_{2}, \mathrm{~Pb} \mathrm{Br}_{2}\right.$, and $\left.\mathrm{Pb} \mathrm{I}_{2}\right)$, only the iodide was found to react photo-electrically. The spectrophotoelectrical sensitivity curve of lead iodide appears to be complex, with an ill-defined maximum in the region of $0.45 \mu$ and a sharply defined maximum at $0.52 \mu$.

The halide salts of silver appear to be sensitive photo-electrically when melted into a vitreous or semivitreous mass. Silver chloride exhibited photo-electrical sensitivity in the region of $0.38 \mu$. Silver bromide has a maximum at $0.46 \mu$. The sensitivity curve of silver iodide appears to be wide and complex, with maxima at about 0.47 and $0.50 \mu$, respectively. In connection with these silver halide salts an examination of samples of silver nitrate and potassium nitrate showed no photo-electrical sensitivity.

Washington, August I 7, 1922. 